\title{
METHYLENETETRAHYDROFOLATE REDUCTASE GENE POLYMORPHISMS IN CARDIOMETABOLIC DISEASES
}

\section{Cristina Hotoleanu, Mihai Porojan, and Mihai Lucian Rusu}

Second Department of Medicine, University of Medicine and Pharmacy Iuliu Hatieganu, Cluj-Napoca, Romania

Although there is growing evidence that C677T polymorphism of the methylenetetrahydrofolate reductase (MTHFR) gene could be considered a risk factor for cardiometabolic diseases associated with elevated levels of homocysteine, the clinical impact and efficiency of therapy remain a matter of debate. The role of A1298C polymorphism of MTHFR in these diseases is still not clearly defined. Most of the studies have shown the correlations between homozygosity for the T677 allele of the MTHFR gene and homocysteine-related cardiometabolic diseases including the metabolic syndrome, diabetes mellitus, ischemic cardiopathy, stroke, and venous thromboembolism. The proposed pathological mechanism of hyperhomocysteinemia involves prothrombotic effects and endothelial dysfunction. Therapy with vitamins B may decrease the homocysteine level in cases with C677T polymorphism whereas the reducing effect on cardiovascular events is not significant. Biomed Rev 2008; 19: 49-52.

Key words: homocysteinemia, methylenetetrahydrofolate reductase polymorphisms, cardiometabolic diseases

\section{INTRODUCTION}

The methylenetetrahydrofolate reductase (MTHFR) gene has been mapped to chromosomal region 1p36.3. MTHFR C677T polymorphism results from a $\mathrm{C}$ to $\mathrm{T}$ transition at the nucleotide position 677 in DNA, leading to the substitution of alanine (C) to valine (T) residue at position 226 in the protein; this results in a decreased basal activity of the enzyme by $50 \%$ (1). Numerous studies have shown the association between homozygous genotype MTHFR 677TT and hyperhomocysteinemia. Due to its multiple roles in different cellular pathways, the amino acid homocysteine is a unique candidate for the study of different cardiometabolic and age-related pathological conditions, namely atherosclerosis, obesity, diabetes mellitus and the metabolic syndrome $(1,2)$ as well as dementia and epilepsy $(3,4)$. The role of homocysteine in

Received 20 November, 2008, accepted 15 December 2008.

Correspondence and reprint request to Dr Cristina Hotoleanu, 9 Iancu Hunedoara str., Cluj-Napoca, Romania.

Tel.: 400744392 203, Fax: 40264580 499, E-mail: cristinaiga@yahoo.com 
predicting risk for atherothrombotic vascular disease has been evaluated in several observational studies in a large number of patients. Hence hyperhomocysteinemia is considered the "cholesterol of nineties" due to the impact on early atherosclerosis; it is established from a large body of studies than even mildly hyperhomocysteinemia is an independent risk factor for cardiovascular diseases (2).

MTHFR represents one of the key enzymes in homocysteine metabolism, involved in remethylation pathway: the conversion of homocysteine to methionine, using the methyl donor provided by the reduction of 5,10-methylene-tetrahydrofolate to 5-methyl-tetrahydrofolate by this enzyme. The intracellular concentration of homocysteine is maintained at low level by remethylation (requiring folate and B12 vitamin as co-factors) and transsulfuration reactions (requiring B6 vitamin as cofactor). The remethylation pathway contributes predominantly to maintenance of the normal fasting homocysteine level whereas the transsulfuration maintains especially the postprandial concentration (5).

The interrelations between homocysteine, MTHFR polymorphisms, vitamins B and folate deficiencies in cardiometabolic diseases are complex. MTHFR polymorphisms result in hyperhomocysteinemia especially when the folate level is low. A recent American study, the third National Health and Nutrition Examination Survey (NHANES III), showed a significant association between low serum folate and increased homocysteine levels in cases with MTHFR C677T genotype as well as the significant decreasing of homocysteinemia concentration by moderate daily folic acid intake. The authors showed the reduction of the impact of MTHFR $677 \mathrm{C}->\mathrm{T}$ on homocysteine levels by moderate administration of folic acid (6). However, some authors showed an independent effect of MTHFR polymorphisms in atherothrombosis and a weak correlation between folate level and homocysteinemia (7). A recent French study showed that 677TT genotype is associated with elevated homocysteine plasma concentration in men, but not in women (5). Some authors showed that not only homozygosity for MTHFR C677T, but also the compound heterozygosity for C677T/A1298C may result in mild hyperhomocysteinemia (8).

\section{MTHFR IN METABOLIC SYNDROME}

The metabolic syndrome is a cluster of factors accumulated in one individual, diagnosed in the presence of at least 3 of the following anthropometric and cardiometabolic risks: waist circumference more than $102 \mathrm{~cm}$ in men and more than 88 $\mathrm{cm}$ in women, blood pressure $>=130 / 85$, triglyceride level more than $150 \mathrm{mg} / \mathrm{dl}$., HDL-cholesterol $<=40$ in men, $<=50$ in women, fasting glucose $>=110 \mathrm{mg} / \mathrm{dl}$. (according to NCEPATP III guidelines) (9). A recent study showed that patients with homozygous MTHFR genotype for T allele are at higher risk for insulin resistance with increasing central adiposity, which is independent of age, gender, body mass index, or metabolic syndrome diagnosis (10).

Several studies showed an association between hypertension, hyperhomocysteinemia and C677T MTHFR polymorphism. It was suggested that this genetic defect could be a factor explaining the increased cardiovascular risk for hypertensive patients by elevated homocysteinemia. However, a direct association between C677T MTHFR polymorphism and hypertension could not been confirmed, indicating that other factors modulate the association between hyperhomocysteinemia and essential hypertension (11).

\section{MTHFR IN DIABETES MELLITUS}

During the last decades, several studies have shown that there may be a link between elevated concentrations of plasma homocysteine and insulin resistance (12). High levels of homocysteinemia and a positive association with microalbuminuria were identified in patients with type 2 diabetes mellitus (13). Studies in rats showed that insulin resistance was associated with hyperhomocysteinemia and changes involving the enzymes of homocysteine metabolism; a stimulation of insulin-induced elimination of methionine was proposed as a possible explanation of this association (14). Other study failed to demonstrate a significant correlation between increased levels of homocysteine and type 1 diabetes mellitus; no significant differences were found in homocysteinemia related to the metabolic control of diabetes (based on glycohemoglobin values) (15). Some authors showed insulin as an independent and significant factor for the variance of homocysteine level, especially in young obese patients (16).

A recent study aimed to determine whether MTHFR C677T and methionine synthase reductase MTRR polymorphisms could be considered risk factors for early microvascular disease in adolescents with type 1 diabetes; the authors concluded that survival without retinopathy was reduced in cases with combined MTHFR 677TT and MTRR 66GG genotype. They also showed that homozygosity for MTHFR 677 TT was related to earlier onset of retinopathy (17). 


\section{MTHFR IN OBESITY}

Obesity as well as overweight was associated with hyperhomocysteinemia; some studies showed a significant association between C677T polymorphism and obesity/overweight. However, a study published in 2008 (18), based on 3 longitudinal studies, The British Women's Heart and Health Study, the Avon Longitudinal Study of Parents and Children and the Copenhagen City Heart Study, failed to demonstrate a significant association between this genetic defect and obesity and showed that the initial positive correlation with homozygosity for MTHFR 677TT was a chance finding (19).

\section{MTHFR IN CARDIOVASCULAR DISEASES}

Hyperhomocysteinemia is considered an independent cardiovascular risk factor; several studies showed that MTHFR C677T genotype is positively associated with arterial and venous thrombotic disease $(20,21)$. On the other hand, MTHFR C677T polymorphism was not significantly associated with cardiovascular diseases $(22,23)$ or venous thrombosis $(24)$. The second common mutation of MTHFR gene was described in 1998 and consists of an A to $\mathrm{C}$ transition at nucleotide 1298 (A1298C) leading to a glutamate to alanine substitution in the MTHFR protein with a decrease in MTHFR activity, especially in homozygous.

\section{THERAPY WITH B VITAMINS}

There are controversies regarding the benefit of vitamins B and folate administration in patients with MTHFR polymorphisms and hyperhomocysteinemia; most of the studies show a decrease in homocysteine levels but not in cardiovascular events $(2,7,25,26)$. Recently was shown that routine screening and therapy of hyperhomocysteinemia with folic acid and vitamins B is not recommended; furthermore, a causal relationship between increased levels of homocysteine and cardiovascular diseases was not confirmed by randomised controlled trials $(27,28)$. A future direction regarding folate therapy could be based on the understanding of (i) caveolae/ caveosome-mediated potocytosis of folate (29) and (ii) nitric oxide metabolism (30).

\section{REFERENCES}

1. Welch G, Loscalzo J. Homocysteine and atherothrombosis. N Engl J Med 1998; 338: 1042-1050.

2. Stanger A, Hermann W, Pietrzik K, Fowler B, J. Geisel $\mathrm{J}$, Dierkes M, et al. On behalf of the D.A.CH.-Liga Homocystein e.V.-D.A.CH.-Liga Homocystein (German,
Austrian, and Swiss Homocysteine Society) Consensus Paper on the Rational Clinical Use of Homocysteine, Folic Acid, and B-Vitamins in Cardiovascular and Thrombotic Diseases- Guidelines and Recommendations. Clin Chem Lab Med 2003; 41:1392-13403.

3. Zhang YD, Ke XY, Shen W, Liu Y. Relationship of homocysteine and gene polymorphisms of its related metabolic enzymes with Alzheimer's disease. Chin Med Sci J 2005; 20:247-251.

4. Stanojlović O, Rasić-Marković A, Hrncić A, Susić V, Macut $\mathrm{D}$, Radosavljević $\mathrm{T}$, et al. Two types of seizures in homocysteine thiolactone-treated adult rats. Behavioral and electroencephalographic study. Cell Mol Neurobiol 2008 Oct 30. In press.

5. Chango A, de Courcy GP, BoissonF, Guilland JC, Barbe F, Perrin MO, et al. 5,10-methylenetetrahydrofolate reductase common mutations, folate status and plasma homocysteine in healthy French adults of the Supplementation en Vitamines et Mineraux Antioxydants (SU. VI.MAX) cohort. Br J Nutr 2000; 84: 891-896.

6. Yang QH, Botto LD, Gallagher M, Friedman JM, Sanders CL, Koontz D, et al. Prevalence and effects of gene-gene and gene-nutrient interactions on serum folate and serum total homocysteine concentrations in the United States: findings from the third National Health and Nutrition Examination Survey DNA Bank. Am J Clin Nutr 2008; 88: 232-246.

7. Nadir Y, Hoffman R, Brenner B. Association of homocysteine, vitamin B12, folic acid, and MTHFR C677T in patients with a thrombotic event or recurrent fetal loss. Ann Hematol 2007; 86: 35-40.

8. Rady PL, Szucs S, Grady J, Hudnall SD, Kellner LH, Nitowsky H, et al. Genetic polymorphisms of methylenetetrahydrofolate reductase (MTHFR) and methionine synthase reductase (MTRR) in ethnic populations in Texas; a report of a novel MTHFR polymorphic site, G1793A. Am J Med Genet 2002;107:162-168.

9. Expert Panel on Detection, Evaluation, and Treatment of High Blood Cholesterol in Adults. Executive summary of the third report of the National Cholesterol Education Program (NCEP) Expert Panel on Detection, Evaluation, and Treatment of High Blood Cholesterol in Adults (Adult Treatment Panel III). JAMA 2001; 285:2486-2497.

10. Ellingrod VL, Miller del D, Taylor SF, Moline J, Holman T, Kerr J. Metabolic syndrome and insulin resistance in schizophrenia patients receiving antipsychotics genotyped 
for the methylenetetrahydrofolate reductase (MTHFR) 677C/T and 1298A/C variants. Schizophr Res 2008;98: 47-54.

11. Garfunkel VAM, Porto PI, Garcia SI, Dieuzeide G, T Kirszner T, Y Plotquin Y, et al. Hyperhomocysteinemia but not MTHFR genotype is associated with young-onset essential hypertension. J Human Hyperten 2003; 17 : 361-364

12. Guven A, Inanc F. Plasma homocysteine levels in patients with metabolic syndrome. Eur J Gen 2004; 1:38-42.

13. Hoogeveen EK, Kostense PJ, Jakobs C, et al. Hyperhomocysteinemia increase risk of death, especially in type 2 diabetes: 5 years follow-up of the Hoorn Study. Circulation 2000;101:1506-1511.

14. Pavia C, Ferrer I, Valls C, Artuch R, Colome C, Vilaseca MA. Total homocysteine in patients with type 1 diabetes. Diabetes Care 2000; 23:84-87.

15. Gallistl S, Sudi K, Mangge H, Erwa W, Borkenstein M. Insulin is an independent correlate of plasma homocysteine level in obese children and adolescents. Diabetes Care 2000; 23:1238-1352.

16. Wiltshire EJ, Fauzia M, Chan A, Donaghue KC. Methylenetetrahydrofolate reductase and methionine synthase reductase gene polymorphisms and protection from microvascular complications in adolescents with type 1 diabetes. Pediatric Diabetes. 2008; 9:348-353

17. Thawnashom K, Tungtrongchitr R, Petmitr S, Praneet PP, Phonrat B, Tungtrongchitr A. Methylenetetrahydrofolate reductase (MTHFR) polymorphism C677T in relation to homocysteine concentration in overweight and obese Thais. Southeast Asian J Tropical Med Public Health 2005; 36: 459-466.

18. Lewis SJ, Lawlor DA, Nordestgaard BG, Tybjaerg-Hansen A, Ebrahim S, Zacho J, et al. The methylenetetrahydrofolate reductase C677T genotype and the risk of obesity in three large population-based cohorts. Eur J Endocrinol 2008;159:35-40.

19. Shmeleva VM, Kapustin SI, Papayan LP, Sobczynska MA, Harrington DJ, et al. Prevalence of hyperhomocysteinemia and the MTHFR C677T polymorphism in patients with arterial and venous thrombosis from North Western Russia. Thromb Res 2003; 111: 351-356.

20. Almawi WY, Ameen G, Tamim H, Finan RR, Irani-Hakime N. Factor V G1691A, prothrombin G20210A, and methylenetetrahydrofolate reductase [MTHFR] C677T gene polymorphism in angiographically documented coronary artery disease. J Thromb Thrombolysis 2004; 17:199-205

21. Kadziela J, Janas J, Dzielińska Z, Szperl M, Gaździk D, Chotkowska E, et al. The C677T mutation in methylenetetrahydrofolate reductase gene, plasma homocysteine concentration and the risk of coronary artery disease. Kardiol Pol 2003; 59:17-26.

22. Kolling K, Ndrepepa G, Koch W, Braun S, Mehilli J, Schomig A. Methylenetetrahydrofolate reductase gene C677T and A1298C polymorphisms, plasma homocysteine, folate, and vitamin $\mathrm{B}_{12}$ levels and the extent of coronary artery disease. Am J Cardiol 2004;93: 12011206.

23. Jen-Shiou L, Ming-Ching S, Woei T, Bodo L.The prevalence of C677T mutation in the methylenetetrahydrofolate reductase gene and its association with venous thrombophilia in taiwanese chinese. Thromb Res 2000; 97: 89-94.

24. Toole J, Malinow M, Chambless L, et al. Lowering homocysteine in patients with ischemic stroke to prevent recurrent stroke, myocardial infarction and death: the Vitamin Intervention for Stroke Prevention VISP randomized trial. JAMA 2004; 291:565-575

25. Bonaa K, Njolstad I, Ueland P, Schirmer H, Tverdal A, et al. Homocysteine lowering and cardiovascular events after acute myocardial infarction. $N$ Engl J Med 2006; 354: 1578-1588.

26. The heart outcomes prevention evaluation (HOPE) 2 investigators. Homocysteine lowering with folic acid and B vitamins in vascular disease. $N$ Engl J Med 2006; 354: 1567-1577.

27. Djurić D, Jakovljević V, Rasic-Marković A, Djurić A, Stanojlović O. Homocysteine, folic acid and coronary artery disease: possible impact on prognosis and therapy. Indian J Chest Dis Allied Sci 2008; 50:39-48.

28. Kaul S, Zadeh AA, Shah PK. Homocysteine hypothesis for atherothrombotic cardiovascular disease: not validated. J Am Coll Cardiol 2006; 48:914-923.

29. Bathori G, Cervenak L, Karadi I. Caveolae - an alternative endocytotic pathway for targeted drug delivery. Crit Rev Ther Drug Carrier Syst 2004; 21:67-95.

30. Djurić D, Vusanović A, Jakovljević V. The effects of folic acid and nitric oxide synthase inhibition on coronary flow and oxidative stress markers in isolated rat heart. Mol Cell Biochem 2007; 300:177-183. 